\title{
Jejunal villous changes associated with farmer's lung
}

\author{
T. J. ROBINSON* \\ M.D., F.R.C.P. \\ MARGaRet HaIRE $\dagger \ddagger$ \\ M.D., F.R.C.Path. \\ S. A. MCMillan $\dagger$
Ph.D., B.Sc.
}
S. D. NeLSON*
F.R.C.Path.

D. Middleton $\dagger$

B.Sc.

J. P. Evans $\dagger$

F.I.M.L.T.

\begin{abstract}
*Graigavon Area Hospital, C. Armagh; †Belfast City Hospital; and $\ddagger$ Department of Microbiology and Immunobiology, The Queen's University of Belfast, N. Ireland
\end{abstract}

\begin{abstract}
Summary
Eighty-one patients with farmer's lung were screened for evidence of coeliac disease by assessing their clinical features, haemoglobin indices, serum vitamin $B_{12}$ and folic acid levels. HLA typing was carried out and the frequency of antireticulin and other autoantibodies was determined. Two out of 21 patients selected for jejunal biopsy had subtotal villous atrophy, a further 6 had partial villous atrophy and 8 out of 21 had increased lamina propria cellularity. The group as a whole had an increased number of intra-epithelial lymphocytes in the jejunal musosa. Sera of 7 out of 81 patients contained antireticulin antibody compared with 2 of 81 control subjects, a difference without significance. Other autoantibodies were not more frequent in the patient than in the control group and were of normal incidence. HLA antigens were also similar in both groups.
\end{abstract}

\section{Introduction}

Various reports have suggested that there is an association between gluten-sensitive enteropathy (coeliac disease) and diffuse interstitial pulmonary disease (Hood and Mason, 1970; Scadding, 1970; Lancaster-Smith, Benson and Strickland, 1971; Karlish, 1971; Morris et al., 1971; Editorial, 1978). Gluten-sensitive enteropathy has been described in patients with extrinsic allergic alveolitis due to both avian and mouldy hay antigens (Berrill et al., 1975; Robinson, 1976a, b) and it has also been found in patients with idiopathic pulmonary fibrosis (Hood and Mason, 1970; Lancaster-Smith et al., 1971). In a study of 57 patients with proved coeliac disease, Lancaster-Smith et al. (1974) found 3 patients with fibrosing alveolitis. Among those 57 patients were 3 with thyrotoxicosis, 2 with insulin-dependent diabetes and one each with cryptogenic cirrhosis of the liver, rheumatoid arthritis and vitiligo; all conditions of possible auto-immune aetiology. This is not surprising, since coeliac disease appears to be associated with increased incidence of autoantibody, and abnormalities of immunoglobulins in both serum and jejunal secretions have been recorded (Lancaster-Smith et al., 1974; Hobbs and Hepner, 1968; Asquith, Thompson and Cooke, 1969; Blecher et al., 1969; Kenrick and Walker-Smith, 1970; Brown et al., 1973; Mawhinney and Love, 1975). Seah et al. (1971) and Stevens et al. (1975) found antibodies to reticulin to be significantly increased in patients with coeliac disease and in patients with dermatitis herpetiformis, which is another condition associated with jejunal villous atrophy. Indeed, the presence of reticulin antibody has been used by Stevens et al. (1975) as a method of screening asymptomatic relatives of coeliac disease patients. In addition, changes in the distribution of HLA antigens have been found in coeliac disease patients (Falchuck, Rogentine and Strober, 1972; Stokes et al., 1972; Keuning et al., 1976; Bach and van Rood, 1976).

Farmer's lung is common in Northern Ireland and in view of previous suggestions of an association of coeliac disease and farmer's lung the authors decided to study a series of patients with farmer's lung to see whether they had an increased incidence of any of the abnormalities which might point to co-existing coeliac disease, latent or overt. This paper reports their findings.

\section{Materials and methods}

Patients diagnosed as having farmer's lung in the years 1968-1975 living in the southern clinical area 
of Northern Ireland were asked to co-operate in the study. The criteria for diagnosis of farmer's lung were a history of exposure to mouldy hay or straw, clinical features as defined under the British Industrial Injuries Act and listed as Occupational Disease No. 48 by the Ministry of Social Security (1967), and antibodies to at least one of the farmer's lung (FLH) antigens. Eighty-one patients (56 females) with ages ranging from 30 to 85 years agreed to take part in the survey. Blood samples were taken for the estimation of blood count, serum vitamin $B_{12}$ and folate, liver function tests, serum autoantibodies and for HLA-A and -B typing. At the time of the study all the patients were living at home and their lung condition was quiescent. Control sera for the autoantibody studies were obtained from blood donors and were matched for sex and, as near as possible, for age.

Twenty-one of the patients consented to undergo a jejunal biopsy. The specimens were examined under the dissecting microscope and the jejunal mucosal changes were graded as normal; partial villous atrophy, where there was distortion and flattening of the villi with a ridged or convoluted appearance; and sub-total villous atrophy, where there was a flat and featureless mucosa. For histological examination the specimens were sectioned and stained with haematoxylin and eosin. If present, flattening of the villi was recorded, as was increased cellularity of the submucosal layers. Intra-epithelial lymphocyte counts were made according to the methods of Ferguson and Murray (1971) and as modified by Fry et al. (1972) and Ferguson (1977). For a comparison, intra-epithelial lymphocyte counts were made in biopsies from 16 patients known to have coeliac disease, 21 with dermatitis herpetiformis and 20 with gastrointestinal symptoms but with histologically normal jejunal mucosa. All the counts were made on slides identified only by their laboratory number.

An indirect immunofluorescent technique was used to detect antibodies in immunoglobulin classes $G, M$ and $A$ in the sera of patients and controls. Autoantibodies to nuclei, smooth muscle, gastric parietal cells, reticulin and mitochondria were detected using as antigen $5-\mu \mathrm{m}$ cryostat sections from a composite block of snap-frozen rat liver, kidney and stomach using the technique described by McMillan and Haire (1975). Antithyroid microsomal and antithyroglobulin antibodies were detected using $5-\mu \mathrm{m}$ sections of human thyrotoxic gland. All tests on patient and control sera were carried out under code.

Sixty-seven patients were tissue typed for 21 antigens of the HLA-A and -B series using a 2-stage microlymphocytotoxicity test (Middleton et al., 1978). HLA-D/DR typing was not available at the time of the study. Blood samples from 200 blood $\stackrel{\Phi}{\stackrel{2}{2}}$ donors of the Northern Ireland Blood Transfusion $C$ Service were used as a control group. Precipitating $\overrightarrow{\vec{s}}$ antibodies to FLH antigens were detected as described by Pepys and Jenkins (1965).

\section{Results}

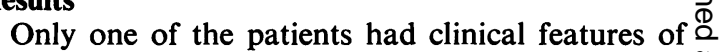
malabsorption, namely weight loss and steatorrhoea.

A 62-year-old female presented with severe $\vec{\circ}$ exertional dyspnoea, widespread bilateral basal crepitations and weight loss of $4 \mathrm{~kg}$. She had been in $\vec{\omega}$ contact with mouldy hay on her farm and there was $\frac{\rho}{\circ}$ a positive titre to Micropolyspora faeni. Chest $\frac{0}{7}$ $X$-ray showed increased lung markings with ill defined patchy areas in both lower zones and the $y$ appearances were described as being consistent with acute farmer's lung. The X-ray abnormalities $\omega$ persisted for several months. An incidental finding of was a haemoglobin of $12.7 \mathrm{~g} / \mathrm{dl}$ with slight macro- o cytosis. Several years previously she had been investigated for a macrocytic anaemia, was found $\vec{z}$ to have a low vitamin $B_{12}$ but did not have achlorhydria on the augmented histamine test. There was diminished absorption of vitamin $B_{12}$ both with and $\overline{0}$ without intrinsic factor, excluding pernicious anaemia.

Co-incidentally with the survey of patients wit $\stackrel{\infty}{\infty}$ farmer's lung she presented 6 years later (Robinso $1976 \mathrm{~b})$ with a 5-month history of frothy diarrhoea, anorexia and a $7 \mathrm{~kg}$ weight loss. Haemoglobin was $9.7 \mathrm{~g} / \mathrm{dl}$ with macrocytosis. Three day faecal fat confirmed steatorrhoea and less than $10 \%$ of a $\frac{\circ}{\Phi}$

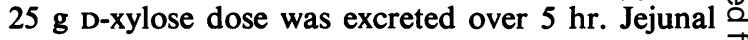
biopsy showed complete absence of villi with some $\overrightarrow{\overrightarrow{0}}$ prominence of lymphocytes and was classified as 3 showing sub-total villous atrophy.

Response to a gluten-free diet was dramatic with disappearance of the diarrhoea, correction of the haemoglobin and a regain of $7 \mathrm{~kg}$ in weight. Subsequent jejunal biopsy showed improvement consistent $\frac{5}{3}$ with a response to a gluten-free diet, confirming coeliac disease.

\section{Blood counts}

Nine patients had lower haemoglobin levels than $\frac{D}{O}$ normal (males $<13 \mathrm{~g} / \mathrm{dl}$ and females $<12.5 \mathrm{~g} / \mathrm{dl}$ ). One of them had microcytosis (MCV $72 \mathrm{fl}$ ) and the $N$ patient with steatorrhoea had macrocytosis (MCV $105 \mathrm{fl})$. In the other 7 , the MCV was within the normal range 75-95 $\mathrm{fl}$.

\section{Vitamin $B_{12}$ and folic acid}

Four patients had serum concentrations of vitamin $B_{12}$ less than normal. One of these had a macrocytosis and a serum vitamin $B_{12}$ of $10 \mathrm{ng} / 1$ (normal range $130-900 \mathrm{ng} / \mathrm{l})$. Serum folate was lower than 
normal $(3 \cdot 5-24.0 \mu \mathrm{g} / \mathrm{l})$ in 15 patients without associated haematological abnormality.

\section{Liver function}

Evidence of gross liver abnormality was not found but in 15 of 81 patients alkaline phosphatase levels were in the range $85-100$ i.u./l, which is slightly above normal.

\section{$H L A$ antigens}

Blood samples from 67 patients were satisfactory for tissue typing. Twenty-four had HLA-B8 antigen $(35.8 \%)$ compared with 69 of 200 blood donors $(34.5 \%)$. The incidence of HLA-B8 in both groups is rather higher than in controls from other regions. This has been previously recognized by Middleton and Martin (1978). The difference between the present control and patient groups in respect of this and all the other HLA antigens tested is not significant.

\section{Autoantibodies}

Serum from 7 patients with farmer's lung had IgG antireticulin antibody titres of $1 / 20$ or greater $(1 / 20,1 / 20,1 / 40,1 / 40,1 / 80,1 / 80,1 / 60)$ compared with 2 of the control sera $(1 / 40,1 / 40)$. This finding does not achieve statistical significance $(P=0 \cdot 18)$. Control and patient groups were closely similar in respect of the other autoantibodies.

\section{Jejunal morphology}

Intra-epithelial lymphocyte counts were high in coeliac disease and dermatitis herpetiformis compared with the miscellaneous group and the counts from the farmer's lung patients did not differ significantly from either the dermatitis herpetiformis or the miscellaneous group (Fig. 1). However, 8 of the 21 farmer's lung patients had biopsies with villous changes and high cellularity of the lamina propria. The positive findings in the patients are collated in Table 1.

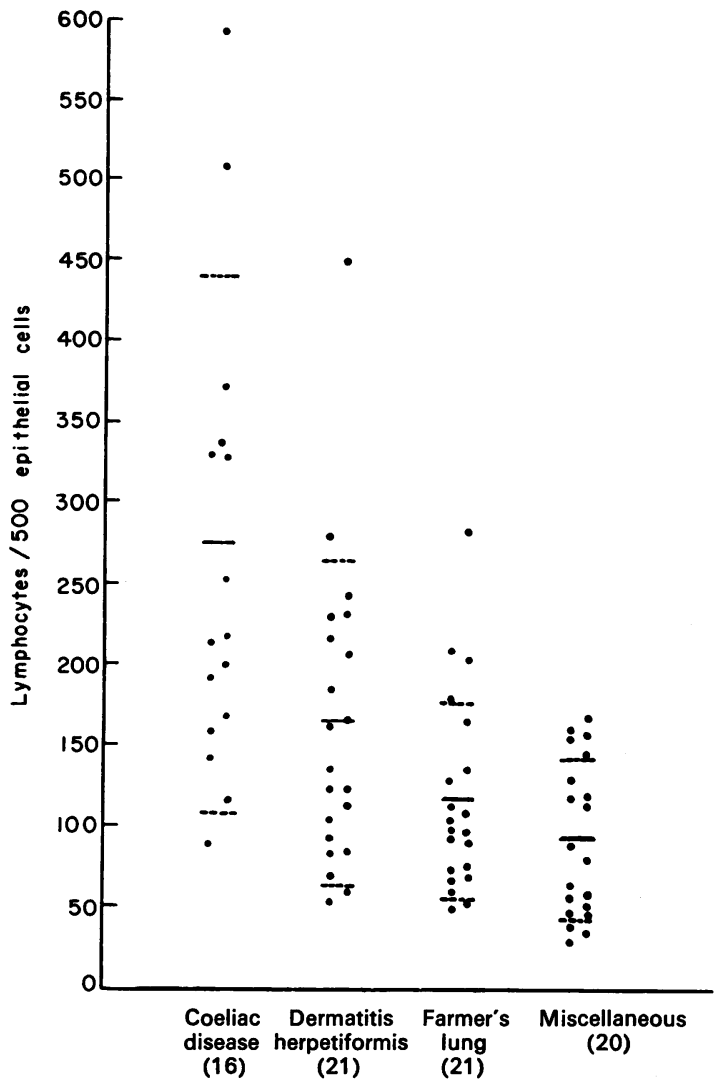

FIG. 1. Intra-epithelial lymphocyte counts.

TABLE 1. Intra-epithelial lymphocytes in jejunal biopsies of patients with farmer's lung, coeliac disease, dermatitis herpetiformis and miscellaneous gastrointestinal disorders

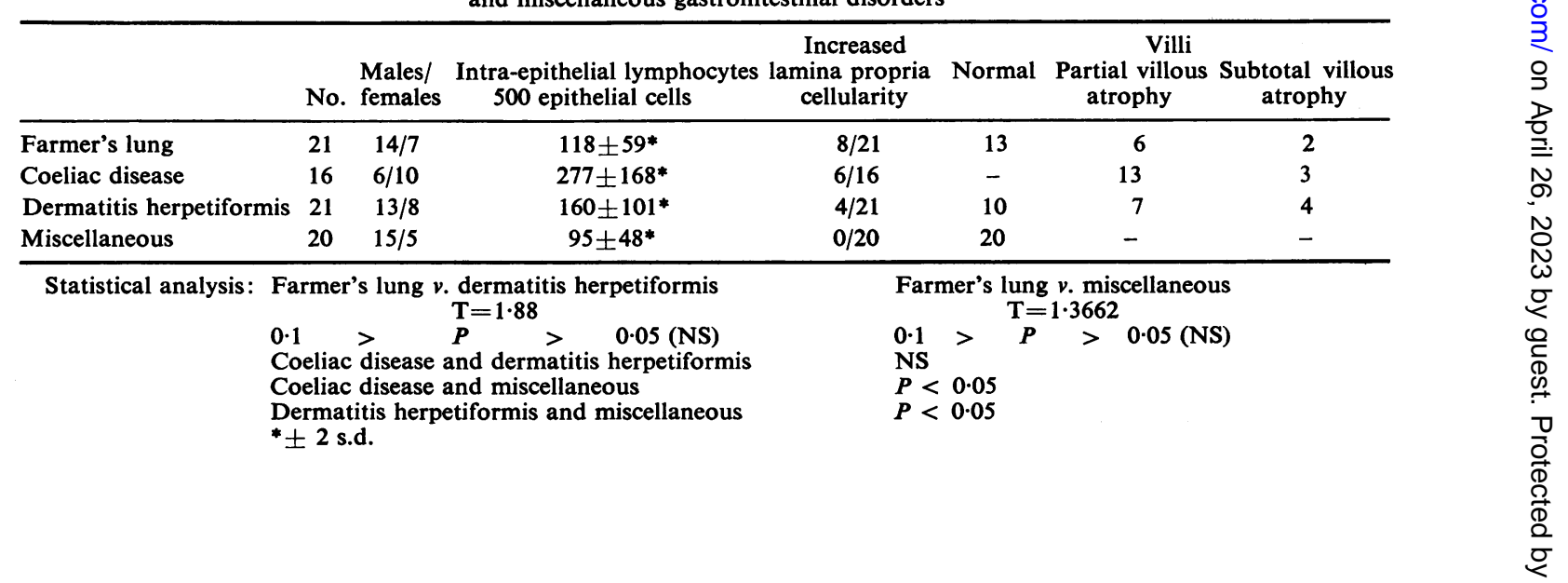




\section{Discussion}

The association of lung disease and coeliac disease is now recognized but there has been dispute about the significance of this finding. Certain types of fibrosing alveolitis have been observed in coeliac disease and it is of interest that a greater proportion of patients with these conditions carry the HLA-B8 antigen than do healthy people. HLA-B8 antigen is also found with increased frequency in many immunopathic disorders such as Graves' disease, Addison's disease, Sjögren's syndrome, chronic active hepatitis and juvenile onset diabetes, diseases in which, as in coeliac disease, there is an increased production of various autoantibodies (Bach and van Rood, 1976; Mackey and Morris, 1972; Eddleston and Williams, 1978). It is tempting, therefore, to relate the concurrence in some way of coeliac disease and lung disease to HLA-B8 antigen; and Flaherty et al. (1975) did suggest that HLA-B8 is increased in patients with farmer's lung. However, the present authors' findings in a much larger series refute this suggestion; and in this they are consistent with those of Berrill and van Rood (1977) who did not find an excess of HLA-B8 in patients with allergic alveolitis due to avian antigens.

The frequency of HLA-B8 in the present patients is perhaps higher than that found in many countries East of the British Isles. The authors believe this to be a real phenomenon, since the frequency of HLA-B8 in population samples from Glasgow, Dublin and Liverpool is similar to that found in both their patient and healthy blood donor populations. This has been commented on by Middleton et al. (1978) and Middleton and Martin (1978). In the event, the frequencies of HLA-B8 in the 'patient' and in 'healthy' populations are closely similar.

There has also been controversy about the nature of antibody reacting against avian antigens in the serum of patients with coeliac disease. Faux, Hendrick and Anand (1978) found precipitins against serum avian antigens in $35 \%$ of patients with coeliac disease who had not had contact with inhaled antigens. Eight out of $\mathbf{4 2}$ patients with bird fancier's lung studied by Eade and Berrill (1978) had jejunal mucosal atrophy. Only one patient had the specific antibody of bird fancier's lung type although in the sera of another 6 patients studied retrospectively the precipitins were uncharacterized. It does appear from their work that coeliac disease can occur in patients with bird fancier's lung but there should be strong reservations about diagnosing bird fancier's lung in patients with coeliac disease except where strict clinical criteria are fully satisfied and the diagnosis of bird fancier's lung should only be made when the specific antibody is present in the patient's serum.

Although it is possible that some of the present patients may have had conditions other than $\frac{2}{\varnothing}$ farmer's lung (e.g. cryptogenic fibrosing alveolitis $c$. occurring co-incidentally in a patient who had been $\underset{\vec{F}}{\vec{F}}$ exposed to mouldy hay) the authors are satisfied $\stackrel{\text { के }}{+}$ that the vast majority, if not all of them, did indeed $\mathrm{C}$ suffer from farmer's lung. All fulfilled strict clinical $\frac{\bar{c}}{\bar{\rho}}$ criteria and all had antibodies to at least one of the $\frac{\text { s }}{\widetilde{\sigma}}$ farmer's lung hay antibodies, a feature which the $\varrho$ authors consider to be central to the diagnosis. Of the 21 patients who underwent jejunal biopsy, $8 \vec{\circ}$ were found to have histological abnormalities. Although 7 out of 81 patients had antireticulin $\vec{\omega}$ antibodies compared with 2 controls, this did not $\frac{\rho}{5}$ reach levels of significance, and other antibodies 0 were not more frequent in the patient than in the 3 . control group and were of normal incidence. जु Clearly the findings do not represent statistically significant evidence of an association between $\omega$ farmer's lung and coeliac disease. Nevertheless, the 6 authors are satisfied that moderate to severe degrees of jejunal villous abnormality may also be present $\stackrel{\circ}{工}$ in association with farmer's lung. They do not know whether these changes presage the development of $Z$ clinically obvious malabsorption in the future, but $\$$ the occurrence of weight loss, overt steatorrhoea or $\frac{3}{6}$ otherwise unexplained anaemia in a patient with $\frac{\Phi}{-}$ farmer's lung should alert the clinician to conside $\vec{\theta}$ the possibility of coeliac disease as an addition diagnosis.

\section{Acknowledgments}

We are very grateful to the patients who so willingly and cheerfully took part in this study. We wish to acknowledge $\frac{O}{D}$

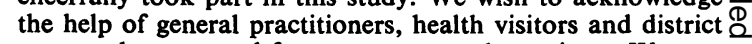
nurses who arranged for us to contact the patients. We owe $\overrightarrow{\vec{B}}$ a great debt of gratitude to the many physicians under $\frac{0}{3}$ whose care the patients had been and especially Dr Edwin James, formerly chest physician in the South Tyrone Hospital, without whose help this project could not have been? considered. Miss Rosalind Beacom, who was a medical student at the time, took many of the blood samples and $\frac{0}{3}$ we are grateful to her and to the Craigavon and Banbridge. District Health Authorities who gave financial support. Dr T.E. Field, and doctors and technicians of the Northern Ireland Blood Transfusion Service kindly made available $ᄋ$ control sera and Dr James Dunbar was very helpful in 3 initiating the survey by supplying names of patients with antibody to farmer's lung antigens. We thank the technical 윽 staff of the Immunology and the Transplantation Immu- $D$ nology Laboratories for their technical help. Finally we must acknowledge the immense debt we owe to Miss Elizabeth Black who did all the secretarial work associated with the $\mathrm{N}$ survey in addition to her normal duties.

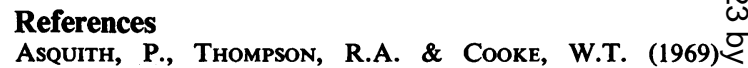
Serum immunoglobulins in adult coeliac disease. Lancet, $\frac{\mathrm{C}}{\mathrm{C}}$
ii, 129 .

BACH, F.H. \& VAN ROOD, J.J. (1976) The major histocompatibility complex-genetics and biology. New

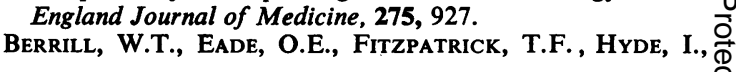


McLeod, W.M. \& Wright, R. (1975) Bird fancier's lung and jejunal villous atrophy. Lancet, ii, 1006.

Berrill, W.T. \& VAN ROOD, J.J. (1977) HLA-DW6 and avian hypersensitivity. Lancet, ii, 248.

Blecher, T.E., BrzechWa-Ajdukiewicz, A., McCarthy, C.F. \& READ, A.E. (1969) Serum immunoglobulins and lymphocyte transformation studies in coeliac disease. Gut, 10, 57.

Brown, I.L., Ferguson, A., Carswell, S., Horn, C.H.W. \& MACsWEEN, R.N.M. (1973) Autoantibodies in children with coeliac disease. Clinical and Experimental Immunology, 13, 373.

EADE, O.E. \& Berrill, W.T. (1978) Coeliac lung disease. Lancet, ii, 1262.

EdDleston, A.L.W.F. \& Williams, R. (1978) HLA and liver disease. British Medical Bulletin, 34, 295.

Editorial (1978) Coeliac lung disease. Lancet, i, 917.

Falchuck, Z.N., Rogentine, G.N. \& Strober, W. (1972) Predominance of histocompatibility antigen HLA-8 in patients with gluten-sensitive enteropathy. Journal of Clinical Investigation, 51, 1602.

Faux, J.A., Hendrick, D.J. \& AnAND, B.S. (1978) Precipitins to different avian serum antigens in bird fancier's lung and coeliac disease. Clinical Allergy, 8, 101.

FERGUSON, A. (1977) Intraepithelial lymphocytes of the small intestine. Gut, 18, 921.

Ferguson, A. \& MURRAY, D. (1971) Quantitation of intraepithelial lymphocytes in human jejunum. Gut, 12, 988.

Flaherty, D.K., Iha, T.H., Chimelik, F., Dickie, H. \& REED, C.E. (1975) HLA-8 in farmer's lung. Lancet, ii, 507.

Fry, L., Seah, P.P., McMinn, R.M.H. \& Hoffbrand, A.V. (1972) Lymphocytic infiltration of epithelium in diagnosis of gluten-sensitive enteropathy. British Medical Journal, 3, 371 .

Hendrick, D.J., Faux, J.A., Anand, B., Piris, J. \& MARSHALL, R. (1978) Is bird fancier's lung associated with coeliac disease? Thorax, 33, 425.

Hobrs, J.R. \& HepneR, G.W. (1968) Deficiency of Mglobulins in coeliac disease. Lancet, $\mathbf{i}, 217$.

HooD, J. \& MASON, A.M.S. (1970) Diffuse pulmonary disease with transfer defect occurring with coeliac disease. Lancet, i, 445.

KARLiSH, A.J. (1971) Coeliac disease and diffuse lung disease. Lancet, i, 1077.

KenRick, K.G. \& Walker-Smith, J.A. (1970) Immunoglobulins and dietary protein antibodies in childhood coeliac disease. Gut, 11, 635.
Keuning, J.J., Pena, A.S., van Hooff, J.P., van Leeuwen, A. \& VAN RooD, J.J. (1976) HLA-DW3 associated with coeliac disease. Lancet, i, 506.

Lancaster-Smith, M.J., Benson, M.K. \& Strickland, I.D. (1971) Coeliac disease and diffuse interstitial lung disease. Lancet, i, 473.

Lancaster-Smith, M.J., Perrin, J., Swarbrick, E.T. \& WrIGHT, J.T. (1974) Coeliac disease and autoimmunity. Postgraduate Medical Journal, 50, 45.

MACKEY, I.R. \& MORRIS, P.J. (1972) Association of autoimmune active chronic hepatitis with HLA-B8. Lancet, ii, 793.

McMillan, S.A. \& Haire, M. (1975) Smooth muscle antibody in patients with warts. Clinical and Experimental Immunology, 21, 339.

MaWhinney, H. \& Love, A.H.G. (1975) Antireticulin antibody in jejunal juice in coeliac disease. Clinical and Experimental Immunology, 21, 394.

Middleton, D., Logan, J.S., Magennis, B.P. \& Nelson, S.D. 1978) HLA antigen frequencies in patients with a Plummer-Vinson stricture. Tissue Antigens, 12, 200.

Middleton, D. \& MARTIN, J. (1978) HLA antigen frequency of Northern Ireland blood donors. Ulster Medical Journal, 47, 171.

Ministry of Social Security (1967) Pneumoconiosis and Allied Occupational Chest Diseases. H.M. Stationery Office, London.

Morris, J.S., ReEd, A.E., Jones, B., Cotes, J.E. \& EdWARdS, J.H. (1971) Coeliac disease and lung disease. Lancet, $\mathbf{i}$, 754.

Pepys, J. \& Jenkins, P.A. (1965) Precipitin (FLH) tests in farmer's lung. Thorax, 20, 21.

Robinson, T.J. (1976a) Coeliac disease with farmer's lung. British Medical Journal, 1, 745.

Robinson, T.J. (1976b) Farmer's lung and coeliac disease. Gut, 17, 398.

Scadding, J.G. (1970) Lung biopsy in diffuse disease. British Medical Journal, 2, 557.

Seah, P.P., Fry, L., Hoffbrand, A.V. \& Holborow, E.J. (1971) Tissue antibodies in dermatitis herpetiformis and adult coeliac disease. Lancet, i, 834.

Stevens, F.M., Lloyd, R., Egan-Mitchell, V., Mylotte, M.J., Fottrel, P.F., Wright, R., McNicholl, B. \& McCARTHY, C.F. (1975) Reticulin antibodies in patients with coeliac disease and their relatives. Gut, 16, 598.

Stokes, P.L., Asquith, P., Holmes, G.K.T., Mackintosh, P. \& CoOKE, W.T. (1972) Histocompatibility antigens associated with adult coeliac disease. Lancet, ii, 162. 